Reply

\title{
Response to Comments by Leo Van Hove on "Mobile Money, Individuals' Payments, Remittances, and Investments: Evidence from the Ashanti Region, Ghana" Sustainability 2018, 10, 1409
}

\author{
Emmanuel Kwablah Apiors ${ }^{1, *}$ and Aya Suzuki ${ }^{2}$ \\ 1 Graduate Program in Sustainability Science Global- Leadership Initiative (GPSS-GLI), The University of \\ Tokyo, Kashiwa 277-8563, Japan \\ 2 Department of International Studies, The University of Tokyo, Kashiwa 277-0882, Japan; \\ ayaszk@k.u-tokyo.ac.jp \\ * Correspondence: emmanuel.apiors@s.k.u-tokyo.ac.jp; Tel.: +81-80-9703-3530
}

Received: 2 November 2018; Accepted: 4 November 2018; Published: 7 November 2018

We very much appreciate Leo Van Hove for the comment of Reference [1]. Below are our replies to the two comments received.

\section{Financial Status and Mobile Use}

We understand the concern that our sample is limited to mobile phone owners rather than the whole population of Ghana, and thus our findings are only robust for mobile phone owners. We agree on this point. The findings for Hypothesis 1 (i.e., financial assets do not matter for mobile money usage) [2] are only applicable for mobile phone owners. That said, we would also like to emphasize that the reason for using only mobile phone owners for our study is to understand why the rate of mobile money usage is low while the rate of mobile phone ownership is extremely high in the country. At the time of the baseline survey, mobile phone penetration (voice call subscription) in Ghana was $135.30 \%$ of the population (Bank of Ghana, n.d.) [3]. That is the puzzle that our research is trying to focus on, and one of the constraints, we suspected, was the financial assets. While the financial barriers to mobile phone ownership, such as the costs of purchasing a mobile phone and a SIM card, do exist, their impact is rather a known fact. Thus, we believe it is more important to study the impact of financial assets on mobile money use among mobile phone owners than to study the same impact among the general public, which includes those who do not own a mobile phone. We intended to have deeper analyses by using the sample of mobile phone owners only.

To add, as the high penetration rate of mobile phones shows, the cost of mobile phone ownership is becoming low in Ghana. A SIM card in Ghana at the time of the baseline survey cost $\$ 0.25$ and a basic ordinary phone cost $\$ 7.5$, while the GDP per capita in 2017 was $\$ 1641.5$ (World Bank) [4]. Hence, in practice, procuring a phone and SIM card is relatively not that expensive.

\section{Mobile Money Use and Savings}

The second concern raised in Reference [1] is that while mobile money savings require a mobile money account, our paper examines the effect of mobile money use on savings, and that is not valid. However, we do not agree with this concern for the following three reasons.

First of all, opening a mobile money account is only required when one wants to use the saving services. While there are users who open accounts in order to benefit from the lower transaction costs of remittances, it is not a requirement to send or receive remittances. Thus, having a mobile money account itself shows the intention of the users to save to some extent. The requirements to open a mobile money account are minimal, as one just needs to have (a) a phone number (SIM) from the 
desired telecom company and (b) an ID card. Thus, we do not think it becomes a barrier for mobile money users to obtain accounts if they wish to save on mobile money. Other mobile money services, such as payments sent and received, remittances sent and received, investments in micro businesses, health, and education, and consumption, do not require mobile money accounts.

Secondly and most importantly, we examined the total expenditure of our respondents, which included payments through methods other than mobile money, such as bank savings for the case of savings. Mobile money engagement may enhance the tendency to save via several mechanisms. One can be the easy access to a saving mechanism on mobile money, as mentioned in our paper [2]. Another mechanism may be that mobile money engagement enhances the financial transaction of the user, which may increase the financial resources that they can save. This could be due to more remittances received or more profits made through micro businesses that relied on mobile money. With the higher financial resources, one may save more, and it may or may not be mobile money savings. If we had restricted our treatment to mobile money account holders in our analyses, we would have excluded the latter potential mechanism and thus underestimated the impact of the mobile money on savings.

Thirdly, similar to the previous point, while the author of [1] refers to TBILL4ALL (Treasury Bill For All) many times in his comments, in our original paper we refer to TBILL4ALL as one of the possible investment activities that an individual could participate in. It is important to note that the investment activity we looked at is not only restricted to one activity on the mobile money platform, but it also encompasses the totality of their micro business investment activities.

For information, we conducted propensity score matching (PSM) and the inverse propensity score weighting regressions (IPSWR) using the mobile money account holder as the treatment variable (Table 1). Mobile money account ownership is statistically significant on the log of yearly savings at a $1 \%$ level across all models, and this is consistent with the results on our original paper. The magnitude of the effect is less (1.124 compared to 1.548 in Reference [2] for PSM and 0.985 compared to 1.363 in Reference [2] for IPSWR) when we use the account ownership as expected. However, this does not mean that our results in Reference [2] are overestimating the impact of mobile money for the reasons discussed above. The magnitudes are less when we use account ownership (Table 1), because this excludes the increased savings for those users who save using means other than mobile money savings.

Table 1. Propensity score matching (PSM) and inverse propensity score weighting regression (IPSWR) results of mobile money account ownership on savings.

\begin{tabular}{|c|c|c|c|}
\hline & \multicolumn{2}{|c|}{ PSM } & \multirow[t]{2}{*}{ IPSWR } \\
\hline & Kennel Common Trim & Radius Caliper & \\
\hline & (1) & (2) & (3) \\
\hline ln (Yearly Saving) & $\begin{array}{c}1.124^{* * *} \\
(0.218)\end{array}$ & $\begin{array}{c}1.066^{* * *} \\
(0.199)\end{array}$ & $\begin{array}{c}0.985^{* * *} \\
(0.275)\end{array}$ \\
\hline
\end{tabular}

Note: For PSM, bootstrapped standard errors are reported in parentheses. For IPSWR, robust standard errors are reported in parentheses. ${ }^{* * *} p<0.01$. Balancing test results for the PSM, which are omitted for brevity but available upon request, show Kernel Common Trim reduces the bias more than Radius Caliper matching. For IPSWR, the covariates included are the same as the ones in our original paper.

Conflicts of Interest: The authors declare no conflict of interest.

\section{References}

1. Van Hove, L. Comment on "Mobile Money, Individuals' Payments, Remittances, and Investments: Evidence from the Ashanti Region, Ghana". Sustainability 2018, 10, 2784. [CrossRef]

2. Apiors, E.; Suzuki, A. Mobile Money, Individuals' Payments, Remittances, and Investments: Evidence from the Ashanti Region, Ghana. Sustainability 2018, 10, 1409. [CrossRef] 
3. Bank of Ghana. Payment Systems Oversight Annual Report. 2017. Available online: https://www.bog.gov. gh/privatecontent/PaymentSystems/PaymentSystemsAnnualReport2017.pdf (accessed on 5 July 2018).

4. World Bank Open Data. Available online: https://data.worldbank.org/indicator/NY.GDP.PCAP.CD? locations $=\mathrm{GH} \&$ view $=$ chart (accessed on 3 July 2018).

(c) 2018 by the authors. Licensee MDPI, Basel, Switzerland. This article is an open access article distributed under the terms and conditions of the Creative Commons Attribution (CC BY) license (http:/ / creativecommons.org/licenses/by/4.0/). 